\title{
O USO DO DESIGN THINKING FOR EDUCATORS NA AVALIAÇÃO DE UM CURSO DE EXTENSÃO PARA IDOSOS NO CONTEXTO DE UMA UNIVERSIDADE ABERTA DA TERCEIRA IDADE
}

\author{
Guilherme Henrique Koerich' \\ Geovana Samuel Oliveira² \\ Thiago Varnier ${ }^{3}$
}

\section{RESUMO}

A educação e o envelhecimento configuram processos permanentes e dinâmicos na vida humana. Neste sentido, as Universidades Abertas da Terceira Idade (UNATIs), dentre outras propostas, oferecem atividades socioeducativas, como cursos de educação não formal para pessoas idosas. A avaliação de curso configura um instrumento didático, com ênfase na interpretação de resultados, que possibilitam a intervenção e a retomada da prática pedagógica. No entanto, não foram encontradas diretrizes e indicadores específicos para a avaliação de cursos de extensão em UNATIs. Diante disso, esta pesquisa objetiva compreender e demonstrar o uso do processo de design thinking for educators na avaliação de um curso de extensão para idosos no âmbito de uma Universidade Aberta da Terceira Idade. O design thinking for educators (DTE) é uma abordagem centrada nos estudantes, para chegar ao novo, a soluções criativas e criar impacto positivo. Desta forma, seus princípios configuram uma forma de pensar ágil, lúdica e criativa, por meio de um conjunto de processos para transformar problemas em oportunidades e soluções colaborativas. A abordagem é composta por cinco fases: 1) descoberta, 2) interpretação, 3) ideação, 4) experimentação e 5) evolução. Como resultados da aplicação deste processo na avaliação do Curso de Monitores, a UNATI pode envolver os estudantes neste processo avaliativo, com vistas a coprodução e cocriação, para reforçar o sentimento de pertencimento, gestão compartilhada e protagonismo da pessoa idosa. A aplicação da abordagem do DTE, demonstrou-se satisfatória para a avaliação do curso, visto que sistematiza o processo de avaliação, e está em consonância com os preceitos das UNATIs, como o protagonismo, ampla participação e integração da pessoa idosa.

Palavras-chave: Design Thinking for Educators. Avaliação Educacional. Núcleo de Estudos da Terceira Idade.

\footnotetext{
1 Doutorando e Mestre em Engenharia e Gestão do Conhecimento. Técnico em Assuntos Educacionais na Universidade Federal de Santa Catarina, Florianópolis, Santa Catarina, Brasil. Orcid iD: https://orcid.org/0000-0003-1585-6998. E-mail: guilherme.koerich1@gmail.com

2 Graduanda em Enfermagem. Estagiária do Núcleo de Estudos da Terceira Idade da Universidade Federal de Santa Catarina, Florianópolis, Santa Catarina, Brasil. Orcid iD: https://orcid.org/0000-0001-7261-91 18. E-mail: contatogeovanaoliveira@gmail.com

3 Mestre em Design. Pesquisador em nível de doutorado na Universidade Federal de Santa Catarina, Florianópolis, Santa Catarina, Brasil. Orcid: https://orcid.org/0000-0003-0584-3077. Email: thiagovarnier1@gmail.com
} 


\title{
THE USE OF DESIGN THINKING IN THE EVALUATION OF AN EXTENSION COURSE FOR THE ELDERLY IN THE CONTEXT OF AN UNIVERSITY OF THE THIRD AGE
}

\begin{abstract}
Education and aging are permanent and dynamic processes in human life. In this sense, as Universities of the Third Age (U3A), among other applications, socioeducational activities, such as non-formal education courses for elderly people. The course evaluation is a didactic instrument, with an emphasis on the interpretation of results, which makes it possible to intervene and recover pedagogical practice. However, no applicable guidelines and indicators were found for evaluating extension courses at U3As. Therefore, this research aims to understand and demonstrate the use of the design thinking process for educators in the evaluation of an extension course for elderly people in the context of a University of the Third Age. Design thinking for educators (DTE) is a student-centered approach to arrive at new, creative solutions and create a positive impact. In this way, its principles configure an agile, playful and creative way of thinking, through a set of processes to transform problems into opportunities and collaborative solutions. The approach consists of five phases: 1) discovery, 2) interpretation, 3) idea, 4) experience and 5) evolution. As the results of the application of this evaluation process of the Course of Monitors, U3A can involve students in this evaluation process, with a view to co-production and cocreation, to improve the feeling of participation, shared management and the role of older people. The application of the DTE approach, shown to be satisfactory for evaluating the course, as it systematizes the evaluation process, and is in line with the U3A's precepts, such as protagonism, broad participation and integration of the elderly.
\end{abstract}

Keywords: Design Thinking for Educators. Educational Evaluation. Center for Senior Studies.

\section{EL USO DEL TÉRMINO DESIGN THINKING FOR EDUCATORS EN LA EVALUACIÓN DE UN CURSO DE EXTENSIÓN PARA PERSONAS MAYORES EN EL CONTEXTO DE UNA UNIVERSIDAD ABIERTA PARA ADULTOS MAYORES}

\section{RESUMEN}

La educación y el envejecimiento son procesos permanentes y dinámicos en la vida humana. En este sentido, las Universidades Abiertas de la Tercera Edad (UNI 3), entre otras propuestas, ofrecen actividades socioeducativas, como cursos de educación no formal para personas mayores. La evaluación del curso es un instrumento didáctico, con énfasis en la interpretación de resultados, que permite la intervención y la reanudación de la práctica pedagógica. Sin embargo, no se encontraron pautas e indicadores específicos para evaluar los cursos de extensión en UNI 3. Por lo tanto, esta investigación tiene como objetivo comprender y demostrar el uso del témino design thinking for educators en la evaluación de un curso de extensión para personas mayores en el contexto de uma Universidad 
Abierta de la Tercera Edad. Design thinking for educators (DTE) es un enfoque centrado en el alumno para llegar a las nuevas soluciones creativas y crear un impacto positivo. Así, sus principios configuran una forma de pensar ágil, lúdica y creativa, a través de un conjunto de procesos para transformar problemas en oportunidades y soluciones colaborativas. El enfoque consta de cinco fases: 1) descubrimiento, 2) interpretación, 3) ideación, 4) experimentación y 5) evolución. Como resultado de la aplicación de este proceso en la evaluación del Curso de Monitores, UNI 3 puede involucrar a los estudiantes en este proceso de evaluación, con miras a la coproducción y la cocreación, para reforzar el sentimiento de pertenencia, la gestión compartida y el protagonismo de las personas mayores. La aplicación del enfoque DTE demostró ser satisfactoria para evaluar el curso, ya que sistematiza el proceso de evaluación y está en línea con los preceptos de la UNI 3, como el protagonismo, la amplia participación y la integración de las personas mayores.

Palabras clave: Design Thinking for Educators. Evaluación Educativa. Centro de Estudios Superiores.

\section{INTRODUÇÃO}

O primeiro programa universitário para idosos com uma interface educacional, surgiu na década de 70 na França. Este programa concebido pelo Professor Pierre Vellas, lança um modelo de Universidade da Terceira Idade na Universidade de Toulouse (ALENCAR; CARVALHO, 2009). As Universidades Abertas da Terceira Idade (UNATIs) têm por objetivo propiciar um ambiente de aprendizagem, e culturalmente de diálogo, com vistas ao exercício da cidadania, ocupação do tempo livre, e o estabelecimento de redes sociais para pessoas idosas (CACHIONI; ORDONEZ, 2017). Este modelo de Universidade se espalhou pelo mundo inteiro, e o Núcleo de Estudos da Terceira Idade da Universidade Federal de Santa Catarina (NETI/UFSC) foi a primeira UNATI Brasileira, no ano de 1982.

Atualmente, o NETI é vinculado a Pró-Reitoria de Extensão e é um Programa de Extensão. O Núcleo é um espaço para realização de atividades principalmente de extensão, integrada com a pesquisa e o ensino, da graduação e pós-graduação da UFSC. Bem como, no NETI possuem ofertas de atividades socioeducativas desvinculadas do ensino superior da universidade, o qual desenvolve atividades de educação permanente de caráter não-formal. Há diferentes cursos neste formato, e em áreas distintas. 
De outro modo, o Curso de Monitores da Ação Gerontológica (CMAG) é uma oferta regular do NETI desde 1990, conforme Parecer N 028/CPE/90. O CMAG é caracterizado como um curso de extensão, o qual tem por objetivo promover a educação para o envelhecimento individual e coletivo, com vistas à prática do voluntariado junto à sociedade.

O curso foi concebido e estruturado nos quatro pilares da educação participativa de Delors (2000), que diz respeito a Aprender a Conhecer, Aprender a Fazer, Aprender a Viver juntos e Aprender a Ser. Neste contexto, - curso aborda de forma transversal a autonomia, protagonismo e a participação cidadã dos sujeitos idosos, como um ser agente e multiplicador do conhecimento em gerontologia, reforçando os preceitos das UNATIs adotados por Cachioni e Ordonez (2017).

As ações educativas desenvolvidas no NETI vêm sendo constantemente avaliadas, com vistas a uma melhor prestação dos seus serviços ao público idoso e a comunidade em geral. Tendo em vista a escassez de diretrizes e recursos específicos para a avaliação de cursos não formais ou de extensão, emergiu a oportunidade de utilizar os princípios do design thinking for educators (DTE) como estratégia avaliativa. Portanto, este artigo tem como objetivo compreender e demonstrar o uso do processo de design thinking for educators na avaliação de um curso de extensão para idosos.

O artigo é apresentado em cinco seções, sendo a primeira esta introdução. A segunda seção aborda o referencial teórico sobre os conceitos basilares acerca das Universidades Abertas da Terceira Idade, Avaliação de Cursos de Extensão e o Processo de design thinking for educators, necessários ao entendimento das análises e resultados apresentados. Na terceira seção, são relatados os procedimentos metodológicos utilizados neste artigo, seguido da quarta seção, onde são descritos os resultados acerca do uso do processo DTE na avaliação de um curso de extensão para idosos, e, por fim, na seção cinco, são apresentadas as considerações finais, bem como a indicação de estudos futuros. 


\section{FUNDAMENTAÇÃO TEÓRICA}

\section{Universidade Aberta da Terceira Idade}

A criação da primeira Universidade Aberta da Terceira Idade (UNATI), em 23 de fevereiro de 1973 na Universidade de Ciências Sociais de Toulouse, na França é um marco do encontro entre a Educação e a Gerontologia (DOLL, 2017). O Professor Vellas (2009), foi quem promoveu a criação, e buscou introduzir uma visão diferenciada das pessoas idosas e sua inserção no ambiente universitário, assim como promover a intergeracionalidade. Após sua criação, este programa educacional tornou-se mais amplo em 1980, com a criação de um centro de pesquisas gerontológicas, onde os idosos tornaram-se protagonistas de seus conhecimentos, e as pesquisas passaram a ser feitas para, com e pelos estudantes idosos (CACHIONI; ORDONEZ, 2017).

Segundo Vellas (2009), as UNATIs passaram a estar presentes em outros países, sendo assim, em 1975, foi criada a Associação Internacional de Universidades da Terceira Idade (AIUTA). Com os 40 anos de existência da associação, seu presidente apontou como principais desafios para as UNATIs a inclusão de novas práticas educativas dos programas por meio de tecnologias; o protagonismo do idoso nas relações intergeracionais e a integração do idoso nas equipes de execução dos programas (AIUTA, 2015). Estes desafios permanecem com o anseio de superação, principalmente no que diz respeito às UNATIs brasileiras.

O levantamento realizado por Cachioni (2012), aponta que existiam no Brasil 200 programas abertos à terceira idade nas instituições de ensino superior, caracterizados em sua maioria por projetos de extensão universitária, na modalidade de educação permanente de natureza não formal (CACHIONI, 2012). Ainda segundo a autora, o Núcleo de Estudos da Terceira Idade (NETI) da Universidade Federal de Santa Catarina (UFSC) foi o primeiro programa brasileiro com características de Universidade Aberta da Terceira Idade, criado em 1982. Atualmente, o NETI tem como missão: 
"Redescobrir, recriar de forma integrada, sistematizar e socializar o conhecimento de gerontologia, desenvolvendo atividades de promoção das pessoas idosas no meio acadêmico e comunitário, como sujeitos em transformação e transformadores" (NETI, 2020).

Desenvolvendo em seu espaço atividades de Ensino, Pesquisa e Extensão junto aos cursos de graduação e pós-graduação da UFSC e instituições de ensino externas, o NETI acredita contribuir com a comunidade catarinense no desenvolvimento de ações gerontológicas de alcance social, articuladas de modo interdisciplinar e multiprofissional, possibilitando processos de ensino e a socialização das pessoas idosas. Deste modo, o NETI é reconhecido como um case de sucesso acadêmico e social, fato que o consagra como o programa de extensão mais longevo da UFSC.

$\mathrm{Na}$ dimensão pedagógica, com a oferta de atividades sócioeducativas para idosos, o NETI efetiva sua intencionalidade na educação permanente e não formal, na formação de cidadãos protagonistas da sua história, com vistas ao empoderamento, interdependência social, autonomia, independência física e funcional. A intenção maior não é a de certificar ou profissionalizar os estudantes idosos, mas sim, de abrir o mundo do conhecimento, e a possibilidade de se aprender ao longo de toda a vida. Isto reafirma o objetivo geral das UNATIs exposto por Veras e Caldas (2004) de elevar os níveis de saúde física, mental e social dos idosos.

$\mathrm{Na}$ oferta de suas atividades sócio-educativas, o núcleo utiliza como referencial teórico-metodológico a estrutura das três grandes áreas da educação em gerontologia: 1) trabalho educacional com pessoas idosas; 2) divulgação de informações sobre o envelhecimento para a população em geral; 3) formação de profissionais que lidam com questões do envelhecimento. Estas áreas integram seis dimensões: socioeducativa, de lazer, compensatória, emancipatória, de atualização e de manutenção das capacidades cognitivas (PETERSON, 1980). As atividades desenvolvidas no NETI buscam integrar estas seis dimensões, de forma indissociável. Contudo, os idosos são protagonistas, com foco na ampla participação, autonomia e integração, conforme os preceitos das UNATIs. 
Curso de Monitores da Ação Gerontológica

Seguindo o pioneirismo do Núcleo de Estudos da Terceira Idade, no ano de 1989 foi realizada uma nova experiência educacional para idosos, por meio da criação do Grupo de Estudos Gerontológicos. Pretendia-se avaliar o interesse do idoso por atividades de cunho intelectual. O resultado positivo estimulou a formulação do Curso de Monitores da Ação Gerontológica (CMAG) (VAHL; GODTSFRIEDT; GUEDES, 1991).

O então CMAG é uma oferta regular desde 1990, conforme aprovação da câmara de Pesquisa e Extensão da UFSC, por meio do Parecer $n^{\circ}$ 028/CPE/90, que autoriza a oferta do curso. O referido curso é caracterizado como um curso de extensão, o qual objetiva promover a educação para o envelhecimento individual e coletivo, por meio do conhecimento aplicado em gerontologia, com vistas a prática do voluntariado.

O CMAG está estruturado nos quatro pilares da educação participativa de Delors (2000), que diz respeito a aprender a conhecer, fazer, viver juntos e ser. Desde a sua criação, o CMAG é o principal curso do NETI, visto que explora as três grandes áreas da educação em gerontologia, por meio da oferta de educação permanente para idosos que serão multiplicadores deste conhecimento e também prestarão serviços voluntários à sociedade (PETERSON, 1980). O curso possui os seguintes objetivos específicos: qualificar pessoas na área da gerontologia, proporcionando novos conhecimentos e o estímulo da prática do voluntariado junto às comunidades; promover a integração social e comunitária das pessoas idosas, por meio da qualificação e criação de novos conhecimentos que permitam o cultivo de um envelhecimento ativo e o exercício contínuo de educação para a cidadania (UFSC, 1990). Seguindo estes objetivos, a estrutura curricular do curso estava organizada em quatro módulos, com disciplinas de diferentes áreas, em especial, dinâmica de grupo, noções de filosofia, gerontologia, noções de psicologia, antropologia, noções de sociologia, noções de saúde, noções de direito, técnicas e práticas da ação gerontológica, além do estágio supervisionado e seminário reflexivo. 
Devido ao referencial teórico-metodológico do curso voltar-se a multiplicação do conhecimento em gerontologia, por meio da prática do voluntariado, evidencia-se sua relevância e necessidade de atualização para atender às necessidades do novo idoso. Segundo Rebouças et al. (2013), o termo "novo idoso" implica no papel social deste, com diferentes características vinculadas ao seu horizonte histórico e diferenças sociais, apresentando o idoso com um novo estilo de vida e identidade social.

Atentos ao exposto, surgiu a necessidade de reestruturação do curso, visto a demanda de um processo educacional diferenciado para a pessoa idosa em seu contexto biopsicossocial e ao processo educativo dinâmico. Diante disto, foi proposto um processo avaliativo para embasar esta reestruturação.

\section{Avaliação de Cursos de Extensão}

A avaliação é um componente fundamental de processos com cunho educativo. Portanto, como lente teórica, partimos do pressuposto nesta pesquisa de que a avaliação de curso gera conhecimentos fundamentais para o planejamento, à ação organizacional e a retomada ou revisão de determinadas práticas (VIANNA, 2004). Existem diferentes modalidades, funções e categorias de avaliação. Dentre estas, a avaliação formativa, a qual possibilita a ação contínua de verificação e acompanhamento de forma processual, possibilitando identificar com mais segurança $\circ$ desenvolvimento das ações propostas, bem como dar 0 seu encaminhamento para melhorá-las ou adequá-las aos objetivos propostos (ARROYO; ROCHA, 2010).

A avaliação de cursos nas instituições de ensino superior, seguem diretrizes e requisitos estabelecidos pelo Sistema Nacional de Avaliação da Educação Superior do Ministério da Educação (SINAES). O Sistema avalia as instituições, seus cursos e o desempenho dos estudantes (SINAES, 2020). O SINAES foi instituído pela Lei $N^{\circ} 10.861$ de 14 de abril de 2004. E acerca da avaliação no âmbito da extensão universitária, o tema é abordado unicamente no Art. $3^{\circ}$, inciso II, o qual dispõe que: 
Art. $3^{\circ}$ A avaliação das instituições de educação superior terá por objetivo identificar o seu perfil e o significado de sua atuação, por meio de suas atividades, cursos, programas, projetos e setores, considerando as diferentes dimensões institucionais, dentre elas obrigatoriamente as seguintes:

II - a política para o ensino, a pesquisa, a pós-graduação, a extensão e as respectivas formas de operacionalização, incluídos os procedimentos para estímulo à produção acadêmica, as bolsas de pesquisa, de monitoria e demais modalidades (BRASIL, 2004).

No âmbito do SINAES, a extensão universitária é avaliada enquanto política institucional. As atividades de extensão são orientadas pela Política Nacional de Extensão Universitária (2012), a qual apresenta a necessidade de implementação de processos de monitoramento e avaliação da extensão universitária, inclusive, com a definição de indicadores para avaliação de ações extensionistas específicas. O documento afirma que a Extensão Universitária "deve ser entendida como processo formativo, prospectivo e qualitativo, a ser mensurado por critérios objetivos (relatório, trabalho escrito, publicação ou comunicação) e subjetivos (compromisso, dedicação)" (POLÍTICA NACIONAL DE EXTENSÃO UNIVERSITÁRIA, 2012, p.59).

A política ainda convida todos os envolvidos com a Extensão Universitária a empreenderem esforços necessários ao aprimoramento e consolidação do Sistema Nacional de Monitoramento e Avaliação da Extensão Universitária. O Fórum de Pró-Reitores das Instituições Públicas de Educação Superior Brasileiras (FORPROEX), por meio da Comissão Permanente de Avaliação da Extensão, está também desenvolvendo um programa, constituído por três projetos, assim denominados: Capacitação em Avaliação da Extensão Universitária, Diagnóstico da Extensão Universitária Brasileira e Avaliação de Impacto dos Projetos do PROEXT/2009 (POLÍTICA NACIONAL DE EXTENSÃO UNIVERSITÁRIA, 2012).

As ações de extensão universitária na UFSC são regulamentadas pela Resolução Normativa N 88/2016/CUn, de 25 de outubro de 2016. Na referida Resolução, dentre outras orientações, cursos de extensão constituem uma ação pedagógica de caráter teórico e/ou prático, com participação de forma presencial, semipresencial ou a distância, com planejamento, 
organização e critérios de avaliação definidos (UFSC, 2016). O documento ainda estabelece que cabe ao coordenador proponente da ação de extensão supervisionar e avaliar o desempenho dos envolvidos na execução das atividades. Não obstante, a Resolução não estabelece critérios ou maneiras de avaliação dos cursos de extensão.

Para Bartnik (2009) há poucos critérios e modelos que norteiam a avaliação de ações extensionistas, sejam elas na forma de programa, projeto, ação ou curso de extensão. A autora ainda situa em sua pesquisa a avaliação de cursos de extensão por meio de questionários e análises qualitativas com os participantes, mas que na maior parte as avaliações são informais, orais ou em forma de relatório final de projeto (BARTNIK, 2009). Para Arroyo e Rocha (2010), somente com a adoção de procedimentos de avaliação rigorosos e sistemáticos, é possível fazer avançar a extensão universitária, e consequentemente, aprimorá-la.

A luz do exposto, não foram situadas avaliações específicas para as ações de extensão na modalidade curso, ou ao menos, não da mesma forma como são abordados pelo SINAES para os cursos superiores. Destacase que a avaliação sugerida nesta pesquisa trata da estruturação, metodologia e conteúdos abordados nos cursos. E não do processo de ensino e aprendizagem pelos discentes. Dado a escassez de proposições sistemáticas sobre o tema, esta pesquisa indica o uso do processo de Design Thinking for educators como uma ferramenta para avaliação de um curso de extensão.

\section{Design Thinking for Educators}

O Design Thinking (DT) é uma metodologia multidisciplinar, com uma vasta área de atuação, ou seja, sua essência é explorar diferentes possibilidades (BROWN, 2010). Neste sentido, Kieling et al. (2013), apontam que a grande diferença desta metodologia é que o pensamento individual não existe, sendo substituído pela coletividade, onde há a expansão do conhecimento. Esta afirmação, pode ser justificada pelo fato do DT apresentar uma abordagem constituída por um processo não linear, cíclico 
e desenvolvido a partir do trabalho colaborativo, do entendimento da necessidade do outro, da geração rápida de ideias e da cocriação e avaliação de protótipos (IDEO, 2009; D.SCHOOL, 2011). O DT é uma forma de pensar e encarar os problemas focando na colaboração e experimentação.

$\mathrm{O}$ uso da metodologia do Design Thinking tem alcançado bons resultados na criação inovadora de produtos, projetos, modelos e serviços sejam eles educacionais ou mercadológicos (BROWN, 2008). Isso porque esta ferramenta permite auxiliar a projetar e idealizar estados futuros, bem como desenvolver e/ou criar produtos, serviços e experiências reais, por meio do processo de design, afinal, o DT começa estabelecendo a correspondência entre as necessidades humanas com os recursos técnicos disponíveis (COOPER; JUNGINGER; LOCKWOOD, 2010).

Diante da sua aplicabilidade, essa abordagem, criada para $\bigcirc$ contexto de gestão e negócios, pode ser utilizada por pessoas que nunca tenham pensado em si mesmas como designers, de modo que possam resolver uma variedade ampla de problemas, o que vem sendo observado em diversas áreas, dentre elas, a educação (BROWN, 2010). Assim, o Design Thinking aplicado à educação - Design Thinking for Educators (DTE), como um modelo de pensamento centrado no ser humano, colaborativo, otimista e experimental, pode ser utilizado para abordar qualquer desafio, haja visto o conjunto consistente de problemas que professores e escolas enfrentam constantemente, ligados ao planejamento e ao desenvolvimento de experiências de aprendizado (currículo), ambientes de aprendizagem (espaços), programas, projetos e experiências escolares (processos e ferramentas) e estratégias, objetivos e políticas (sistemas) (KIT DT, 2014).

No tocante, em 2010 educadores da Riverdale, Estados Unidos da América, colaboraram com a IDEO para desenvolver o "kit de ferramentas" do Design Thinking for Educators (RIVERDALE, 2014). Este material propõe métodos e processos do design adaptados para a sala de aula, currículo, ambientes de aprendizagem e experiências de interações com outros educadores (DT TOOLKIT, 2011). Em 2011, foi lançada a primeira versão do 
material, traduzido para o português pelo Instituto Educadigital sob a licença Creative Commons, denominado "Design Thinking para Educadores".

O processo de design é o que coloca a metodologia do DTE em ação, a fim de gerar e aprimorar ideias com uma abordagem estruturada. Esse processo acontece por meio de cinco fases, a citar: 1) Descoberta; 2) Interpretação; 3) Ideação; 4) Experimentação; 5) Evolução. Essas fases auxiliam no seu desenvolvimento, desde a identificação do desafio até a construção da solução, conforme pode ser observado na Figura 1.

FIGURA 1 - Fases e Passos do Design Thinking for Educators PROCESSO DE DESIGN THINKING NA PRÁTICA

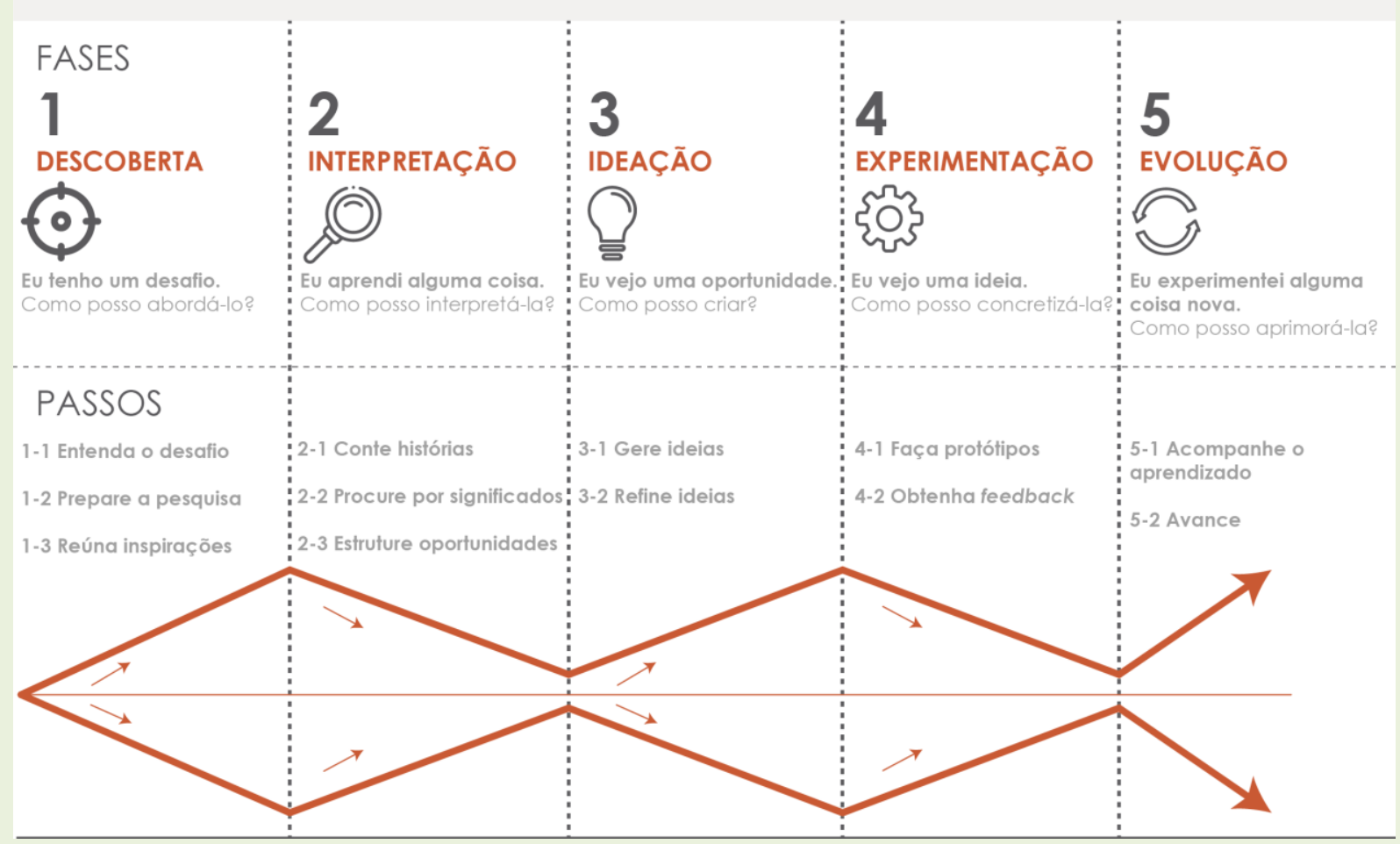

Fonte: [Adaptado de (DT TOOLKIT, 2011, p. 15)].

De acordo com o Kit DT (2014) o primeiro passo antes de partir para as etapas do Design Thinking é definir o desafio, ou seja, o problema específico e intencional a ser resolvido. Assim, este desafio deve ser passivel de compreensão, ação e abordagem. Portanto, deve ter um escopo claro e bem definido. Além disso, o desafio envolve o grupo de pessoas com o qual o problema se relaciona, por exemplo, outros educadores, mães e pais de 
alunos, comunidade ou os próprios estudantes. Com o desafio definido, as cinco fases poderão ser executadas, conforme detalhamento a seguir.

Na Fase 1- Descoberta, o primeiro passo é compreender o desafio que foi definido a partir do compartilhamento do que cada um da equipe sabe. Assim como a definição do público a ser trabalhado, e o refinamento do plano. Depois a pesquisa será preparada com a identificação de fontes de inspiração, seleção dos participantes da pesquisa, elaboração de roteiro de perguntas e preparação para o trabalho de campo. Por fim, é realizado a coleta de inspirações que envolvem o mergulho no contexto por meio da busca de ambientes similares, conhecimentos de especialistas e usuários.

Adiante, na Fase 2- Interpretação, os dados serão transformados em insights (percepções). Inicialmente é documentado o que foi aprendido a partir da observação e posteriormente essas histórias serão compartilhadas com a equipe, o que favorecerá a criação das oportunidades e ideias. Em seguida, será realizado uma procura por significados das histórias contadas por meio da identificação de temas, das descobertas e insights. Por fim, as oportunidades serão estruturadas por meio de diagramas e modelos que irão organizar informações complexas.

Na Fase 3- Ideação, ocorre a geração de várias ideias. A sessão de brainstorming (técnica criativa para tempestade de ideias) deve ser planejada para que seja possível aproveitá-la ao máximo. A atmosfera do brainstorming deve ser segura e positiva para criar todos os tipos de ideias sem julgamentos. As ideias promissoras apresentadas serão selecionadas e depois esboçadas. Por fim, as ideias são refinadas de modo que possam ser desenvolvidas e refinadas cada vez mais.

Já na Fase 4- Experimentação, é o momento de dar vida às ideias, por meio da criação de um protótipo. Esse protótipo poderá ser de diferentes formas, como um storyboard (experiência completa da ideia ao longo do tempo por meio de uma série de imagens, esboços, desenhos), um diagrama, uma história, um anúncio, um modelo, uma maquete, uma encenação, produção de um material digital, dentre outros. Em seguida, os 
protótipos podem ser compartilhados de modo a obter o feedback (retorno de opiniões).

Por fim, na Fase 5- Evolução, ocorre o desenvolvimento do conceito do projeto/atividade/ação ao longo do tempo. Aqui será feito o acompanhamento do aprendizado por meio do impacto alcançado e da documentação do processo. A seguir, serão planejados os próximos passos para que outras pessoas possam ser envolvidas e se construa uma comunidade ao redor do projeto.

\section{PROCEDIMENTOS METODOLÓGICOS}

A pesquisa ora apresentada parte de uma abordagem qualitativa, pois realiza uma coleta de dados sem medição numérica para descobrir e aprimorar perguntas de pesquisa no processo de interpretação (SAMPIERI; COLLADO; LUCIO, 2013). Em estudos qualitativos ou interpretativos, o pesquisador realiza uma imersão sustentada e intensa no fenômeno e nas particularidades do estudo, com o objetivo de observar, interpretar e descrever suas observações (MERRIAM, 2009).

Dado a caracterização interpretativa da pesquisa, seus objetivos norteadores a classificam como uma pesquisa exploratório-descritiva. $\mathrm{Na}$ pesquisa descritiva são abordados quatro aspectos essenciais: descrição, registro, análise e interpretação de fenômenos (MARCONI; LAKATOS, 2007). A pesquisa descritiva requer uma etapa exploratória, a qual ajuda 0 pesquisador a se familiarizar com o fenômeno até então desconhecido, e a obter informações para realizar uma pesquisa mais completa no contexto específico (SAMPIERI; COLLADO; LUCIO, 2013). Desta maneira, foram realizados estudos exploratórios bibliográficos para a compreensão do processo de Design Thinking for Educators. A partir do entendimento teórico do processo, foi concebido um seminário avaliativo do curso em questão, com o envolvimento de educadores e educandos.

A pesquisa exploratória foi realizada com a adoção do procedimento técnico de pesquisa bibliográfica, a qual é composta por fontes secundárias, que abrange a literatura tornada pública acerca do tema estudado 
(FACHIN, 2006). Nesta etapa foram identificados estudos que corroboram para a fundamentação teórica da pesquisa.

Já o procedimento técnico utilizado para observação e descrição do fenômeno estudado foi o estudo de caso. No estudo de caso é realizado uma pesquisa intensa para a compreensão, como um todo, do assunto investigado (FACHIN, 2006). Nesta pesquisa, será abordado um caso específico acerca da avaliação do Curso de Monitores da Ação Gerontológica do Núcleo de Estudos da Terceira Idade da UFSC.

Quanto a sua natureza, a pesquisa realizada é de natureza aplicada, uma vez que seus resultados almejam ser empregados ou utilizados na prática, na resolução de problemas concretos (MARCONI; LAKATOS, 2007). A pesquisa foi desenvolvida em três etapas, de acordo com os objetivos propostos. A primeira etapa da pesquisa foi denominada de 01) Fundamentação Teórica (exploratória), seguida da etapa 2) Aplicar (estudo de caso) e a última etapa 3) Descrever (pesquisa descritiva).

\section{Materiais e Métodos}

Na primeira etapa (Fundamentação teórica) foi realizada uma busca bibliográfica assistemática em artigos científicos e livros acerca dos temas da pesquisa. Assim, foram pesquisados sobre Universidades Aberta da Terceira Idade, com um olhar especial ao NETI/UFSC e a proposição do curso de Monitores da Ação Gerontológica. Bem como, estudos relacionados à avaliação de cursos de extensão e design thinking for educators. Nesta pesquisa as ferramentas de design thinking foram utilizadas como recursos para avaliação de curso.

Na segunda etapa (Aplicar), foi aplicado o processo de DTE com os stakeholders. Para tal, realizou-se um seminário com docentes, corpo técnico-administrativo, egressos e alunos do curso. A programação da atividade estruturou-se em dois blocos. No primeiro bloco, no período matutino, foi realizado uma mesa redonda com quatro docentes convidados, abordando o referencial teórico metodológico do curso (Filosofia do Envelhecimento; Pensamento Complexo de Edgar Morin; 
Educação Participativa de Paulo Freire; e Aspectos da Ação Comunitária e Voluntariado). Já no segundo bloco, no período vespertino, fora realizado o Workshop, para a aplicação dos materiais desenvolvidos; mapa de simpatia e quadro de potencialidades e fragilidades.

$\mathrm{Na}$ terceira etapa (Descrever), é apresentado os resultados obtidos durante a realização do workshop e o pós evento. Para apresentar os resultados do Workshop seguiu-se de forma progressiva as fases e passos propostos no Processo de Design Thinking for Educatiors. No entanto, os dados obtidos foram compilados em uma planilha de excel e posteriormente analisados para diagramação de uma síntese visual em forma de nuvem de palavras, cuja finalidade foi emergir os principais apontamentos indicados pelos educandos para a melhoria do referido curso.

\section{RESULTADOS}

O ponto de partida do processo, ou do desafio, foi a avaliação de um curso de extensão para pessoas idosas, uma oferta regular desde 1991, do Núcleo de Estudos da Terceira Idade (NETI) da Universidade Federal de Santa Catarina (UFSC). Com a avaliação, tem-se o objetivo de reestruturar o curso, com vistas a manter sua proposta e as principais características, em prol à garantia da sustentabilidade e oferta contínua, e a ampla participação dos educandos idosos. A avaliação possibilitará a retomada e revisão das práticas, com vistas a adequação dos objetivos propostos (VIANNA, 2004; ARROYO; ROCHA, 2010).

Conforme apresentado nos procedimentos metodológicos, os resultados desta pesquisa serão apresentados em consonância com as fases e passos do processo de Design Thinking for Educators (DT TOOLKIT, 2011). A Figura 2 apresenta a primeira fase (DESCOBERTA), estruturada em três passos: 1.1 Entenda o desafio; 1.2 Prepare a pesquisa e 1.3 Reúna inspirações. 


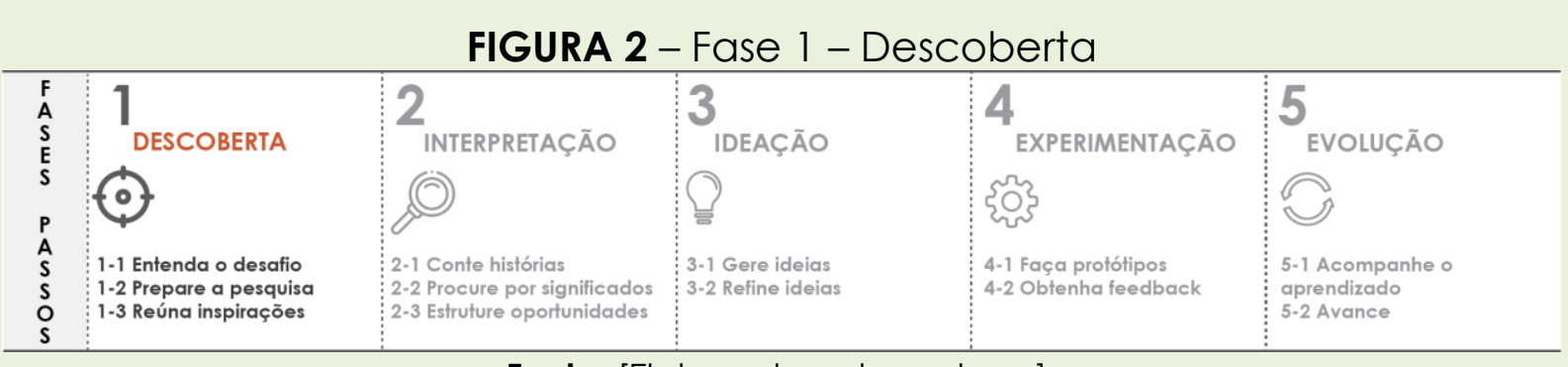

Fonte: [Elaborado pelos autores].

Atentos aos procedimentos desta etapa, foi realizada uma reunião com a equipe de profissionais que atuam diretamente junto ao curso, para compreensão e revisão do desafio. A coordenação do curso realizou uma apresentação com algumas dificuldades encontradas nos últimos tempos, os quais apresentavam desafios de caráter estrutural, em especial sobre a rotatividade de professores voluntários, a correlação com a reestruturação da grade de conteúdos ofertados e o formato das disciplinas. Havia o entendimento por parte da coordenação, da necessidade de algumas alterações, sem perder a proposta do curso. Os envolvidos realizaram um brainstorming, com o compartilhamento de vivências, experiências e conhecimentos acerca da sua atuação no curso, em diferentes aspectos, tais quais sejam relativos ao perfil do estudante, estrutura conceitual, corpo docente, grade curricular, relação com os egressos, dificuldades de aprendizagem dos estudantes, infraestrutura física, dentre outros aspectos.

A reunião ainda que próspera, não estava levando em consideração as percepções e o protagonismo dos estudantes idosos acerca do curso (CACHIONI, 2017), e que até o presente, eram desconhecidas ou especuladas pelos profissionais. Com isto, foi definido que o público desta ação avaliativa são os estudantes do curso, os quais experienciam na prática o curso. Assim, emergiu a descoberta dos principais desafios: Como os estudantes se percebem neste curso? Qual a adequação do currículo com a proposta do curso e o perfil do estudante? $O$ atual formato e a estruturação estão adequados?

Com estas inquietações e o anseio por respostas, fez com que o grupo deliberasse pela realização de um evento disruptivo e com uma metodologia ativa adequada para o público idoso. Este evento, assim 
apresentado para os estudantes, é uma estratégia de pesquisa e coleta de campo, o qual foi denominado "III Seminário Reflexivo do Curso de Monitores da Ação Gerontológica do NETI" em formato de mesa redonda e workshop. O evento teve por objetivo refletir acerca do referencial teórico metodológico norteador do curso, e identificar coletivamente as principais fragilidades e potencialidades do curso, com vistas a subsidiar uma nova proposta pedagógica que atenda as atuais especificidades do envelhecimento humano e do curso, de modo sustentável e inovador. Definiu-se como público alvo do evento, os estudantes regulares e egressos (alumni), docentes, palestrantes, equipe técnica-administrativa e discentes dos cursos de graduação da UFSC.

O evento foi planejado pela equipe técnica de servidores e discentes dos cursos de graduação, os quais estão em estágio não obrigatório ou curricular, assim como, discentes que integram projetos de pesquisa e extensão junto ao NETI. A metodologia do trabalho fora embasada no Design Thinking (DT), no qual a colaboração e a cocriação são elementos basilares, bem como desta pesquisa (BROWN, 2010). Neste sentido, elaborouse um roteiro do trabalho em campo, com cronogramas, etapas, recursos materiais e de pessoal. O evento foi planejado com vistas ao passo 1.3 reúna inspirações (DT TOOLKIT, 2011). E para isto, a equipe realizou uma imersão no contexto do curso, seus desafios e oportunidades. Assim, o evento foi então organizado em dois períodos.

No primeiro período, realizou-se uma atividade de acolhimento e integração entre os participantes. Esta etapa fora importante para promover a integração entre os participantes, aspecto essencial em trabalhos colaborativos. Na sequência, realizou-se uma mesa de debates com professores que atuam no curso e professores convidados, com vistas a subsidiar inspirações para que os estudantes fizessem emergir as potencialidades e fragilidades do curso. Os temas abordados dizem respeito às bases filosóficas metodológicas do curso (VAHL; GODTSFRIEDT; GUEDES, 1991). E no segundo período, realizou-se o workshop, composto por atividades alicerçadas em metodologias ativas, interativas e de cocriação. 
Para o desenvolvimento desta pesquisa de campo, foram atribuídos diferentes papéis entre os membros da equipe. Dentre estes, o de facilitador, designado para acompanhar as atividades dos grupos de trabalho (GTs). A função do facilitador é zelar pelo bom desenvolvimento da atividade, e na articulação com os organizadores; promover a execução da metodologia proposta; monitorar o tempo; reportar aos organizadores qualquer dúvida sua ou do grupo; registrar e reunir as informações e conhecimentos construídos pelo grupo de forma imparcial (redator); e propor a eleição de um relator do GT. Cada GT possuia um facilitador, que foi previamente capacitado, e dispõe de um manual com orientações.

Outro papel atribuído foi o de Relator. O relator é responsável por apresentar os resultados do seu GT aos demais participantes do workshop. O relator é um membro do GT, ou seja, um estudante ou egresso do curso. Ainda sobre a equipe, houve a designação de um moderador, tendo como atribuição conduzir e apresentar informações sobre o andamento de cada etapa, controlar o tempo e esclarecer dúvidas.

Ainda na etapa descoberta, o planejamento do workshop contou com a definição de materiais e métodos a serem utilizados, com vistas a promover a cocriação e colaboração entre os participantes. Estes materiais sistematizam perguntas e roteiros para emergir as principais percepções dos estudantes acerca do curso. Foram utilizados dois materiais norteadores para o workshop. O primeiro foi o "Mapa de Simpatia", uma adaptação do Mapa de Empatia. O mapa de empatia desenvolvido pela XPlane compõe um conjunto de ferramentas de design centradas no ser humano. A ferramenta foi criada para ajudar equipes a desenvolver uma compreensão profunda, compartilhada e empática de seus clientes (PEREIRA, 2017). Assim, visando compreender como os estudantes se percebem e avaliam o curso, foi desenvolvido o Mapa de Simpatia, como sujeito da avaliação (Figura 3). 
FIGURA 3 - Mapa da Simpatia

MAPA DA SIMPATIA - CURSO DE MONITORES DA AÇÃO GERONTOLÓGICA

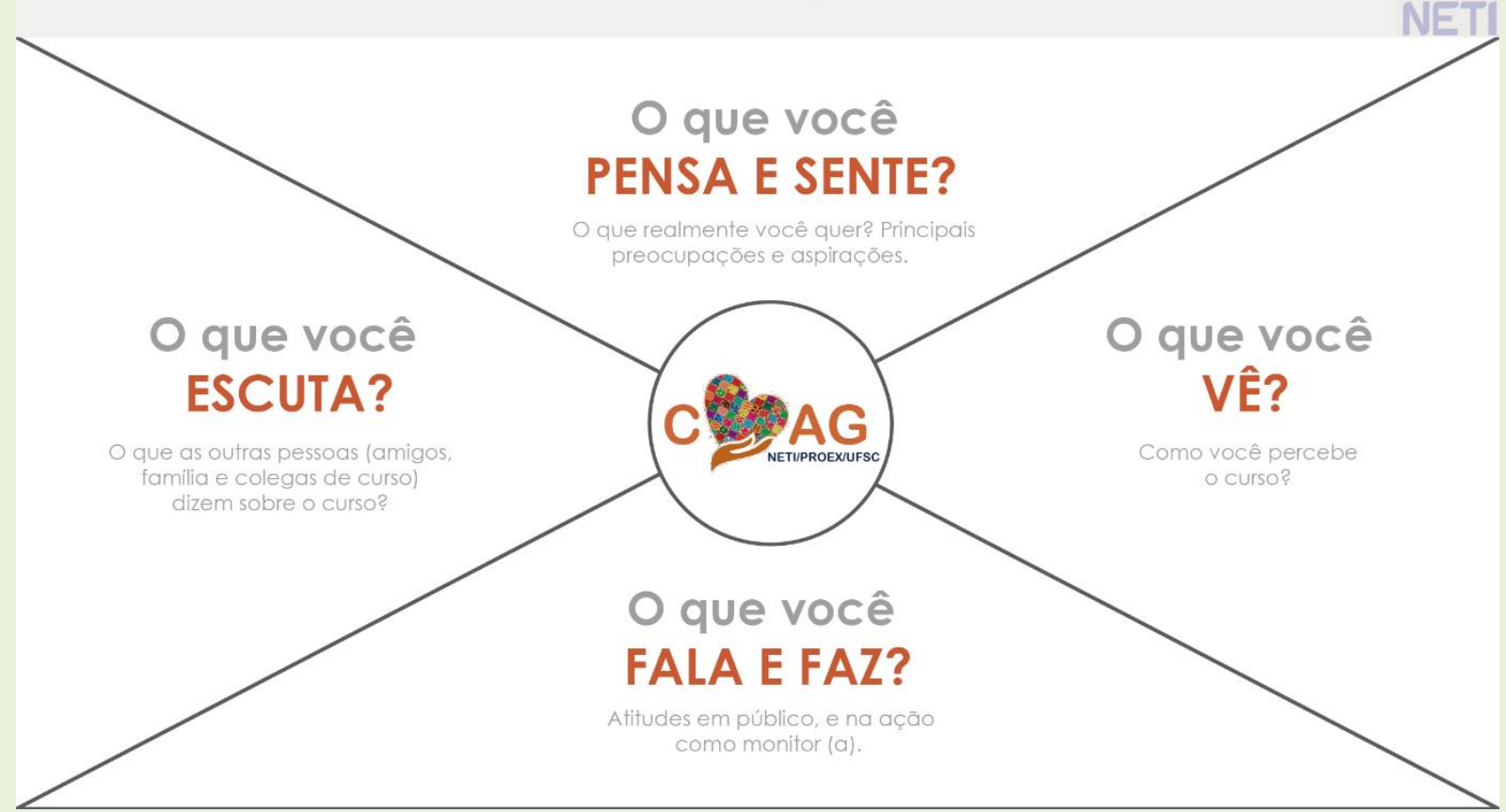

Fonte: [Elaborado pelos autores com base em (PEREIRA, 2017)].

O mapa da empatia ainda apresenta em sua base duas colunas, separando as dores e ganhos. E com isto, foi elaborado um outro quadro para os estudantes elencarem as potencialidades e fragilidades que percebem no curso (Figura 4).

FIGURA 4 - Quadro de Potencialidades x Fragilidades QUADRO DE POTENCIALIDADES E FRAGILIDADES

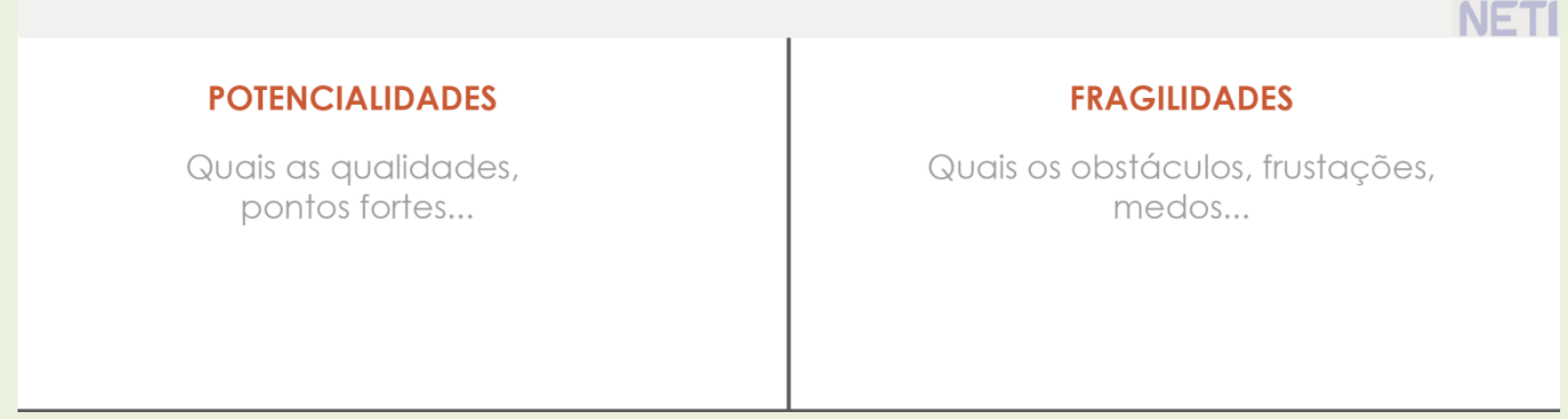

Fonte: [Elaborado pelos autores com base em (PEREIRA, 2017)].

Estes materiais foram norteadores para as atividades do workshop. Assim como, contribuíram significativamente para o processo de avaliação coletiva e colaborativa do curso. 
A segunda fase do processo DTE (INTERPRETAÇÃO), congrega os passos: 2.1 Conte histórias; 2.2 Procure por significados e 2.3 Estruture oportunidades (DT TOLKIT, 2011), conforme apresentados na Figura 5, a seguir.

FIGURA 5 - Fase 2 - Interpretação

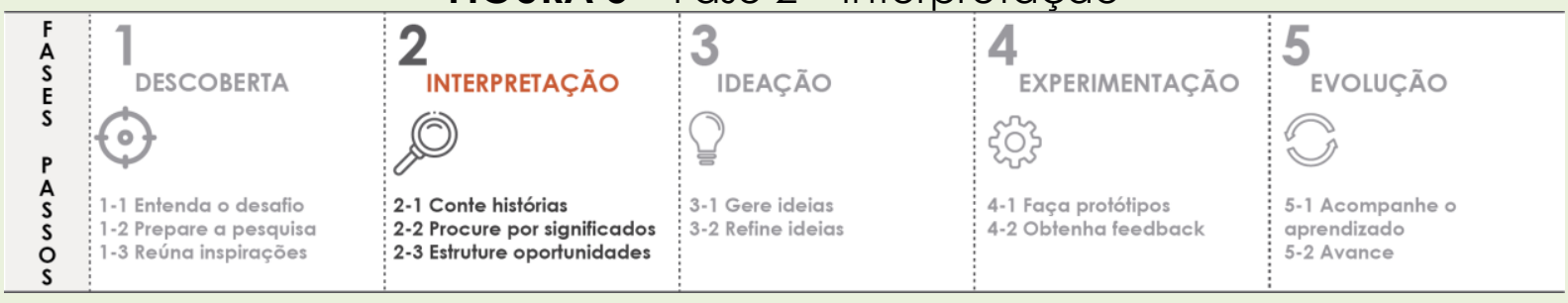

Fonte: [Elaborado pelos autores].

O evento foi estruturado para atender os passos supracitadas. Deste modo, foi realizado em uma sala de capacitações ampla e organizada, de maneira que comporte a interação entre os participantes. A programação do evento fora organizada em dois períodos. No primeiro período, foram realizadas apresentações teóricas, por professores convidados e docentes que atuam no curso, em aderência a etapa 2.1. A proposição foi semear reflexões e apresentar a base filosófico metodológica do curso. Deste modo, a apresentação ocorreu em forma de mesa redonda, para a discussão dos temas, quais sejam, a Filosofia do Envelhecimento, o Pensamento Complexo de Edgar Morin, Educação Participativa de Paulo Freire e Aspectos da Ação Comunitária e Voluntariado. Cada docente realizou sua explanação por 20 minutos, e após as apresentações, houve um debate entre os participantes.

No segundo período do evento, com a participação direta dos estudantes, egressos e professores, foi realizado o workshop com trabalhos em grupo, mediado por uma dinâmica de cocriação entre os participantes. Para tal, realizou-se uma dinâmica de grupo para a composição dos Grupos de Trabalho (GTs). A dinâmica foi conduzida e elaborada por uma estudante egressa do curso, com o qual foram divididos seis grupos. Após a composição dos GTs, o moderador do workshop apresentou a metodologia dos trabalhos aos participantes. 
Inicialmente, utilizando o "mapa de simpatia", objetivou-se saber o que cada participante "pensa e sente", "vê", "fala e faz", e "escuta" acerca do tema explorado, durante o curso. Estas perguntas são bem amplas, e os participantes foram orientados a explicitar aquilo que viesse em suas mentes, sem a necessidade de refinar suas ideias e percepções. Cada participante recebeu o material impresso (papel A3), acompanhado de post-it e canetas, para preenchimento individual, sem a necessidade de identificar-se. Este material sistematiza as histórias e observações que os estudantes idosos têm a compartilhar. Esta atividade teve por objetivo fazer emergir percepções e reflexões individuais sobre o curso.

Dado o preenchimento individual do mapa, foi estabelecido um tempo para cada grupo socializar suas percepções individuais com os demais membros do GT. Com a socialização, os membros de cada GT estruturaram um quadro de fragilidades e potencialidades. Esta atividade objetiva dar subsídios para a construção coletiva de melhorias para o curso.

Os materiais utilizados possibilitaram que os participantes tivessem diferentes insights. Além da sua percepção individual, em grupo, também foram debatidas as principais potencialidades e fragilidades do curso. A partir desta discussão, e dos pontos elencados em cada GT, sejam elas fragilidades ou potencialidades, foram então compartilhadas com os demais participantes do workshop, pelo relator de cada GT. Com isto, foi construído um painel, com as fragilidades e potencialidades, e os estudantes foram convidados, na sequência, à propor soluções para as fragilidades, tendo como recurso as potencialidades do curso. Assim, os insights foram transformados em possíveis ações, debatidas na terceira fase do processo.

Deste modo, a partir da socialização dos insights apresentados na fase 2 em cada grupo, tendo como base a discussão das potencialidades e fragilidades do curso na visão dos estudantes, na Fase 3, será desenvolvida a construção coletiva de ideias para novas adequações no curso.

A terceira fase (IDEAÇÃO), é composta pelos passos 3.1 Gere ideias e 3.2 Refine ideias (DT TOLKIT, 2011), conforme apresentados na Figura 6. 
FIGURA 6 - Fase 3 - Ideação

\begin{tabular}{|c|c|c|c|c|c|}
\hline $\begin{array}{l}F \\
\text { A } \\
\text { S } \\
\text { E } \\
\text { S } \\
\text { P } \\
\text { A } \\
\text { S } \\
\text { S } \\
\text { S } \\
\text { S }\end{array}$ & $\begin{array}{l}1 \\
\text { DESCOBERTA } \\
1-1 \text { Entenda o desafio } \\
1-2 \text { Prepare a pesquisa } \\
1-3 \text { Reúna inspiraçōes }\end{array}$ & $\begin{array}{l}2 \\
\text { INTERPRETAÇÃO } \\
\text { (O) } \\
2-1 \text { Conte histórias } \\
2-2 \text { Procure por sigificados } \\
2-3 \text { Estruture oportunidades }\end{array}$ & $\begin{array}{l}3 \\
\text { IDEAÇÃO } \\
\\
30 \\
3-1 \text { Gere ideias } \\
\text { 3-2 Refine ideias }\end{array}$ & $\begin{array}{l}4 \\
\text { EXPERIMENTAÇÃO } \\
\text { 4. } \\
4-1 \text { laça protótipos } \\
4-2 \text { Obtenha feedback }\end{array}$ & $\begin{array}{l}5 \\
\text { EVOLUÇÃO } \\
S_{5-1 \text { Acompanhe o }} \\
\text { aprendizado } \\
5-2 \text { Avance }\end{array}$ \\
\hline
\end{tabular}

Fonte: [Elaborado pelos autores].

Nesta fase cada GT estruturou oportunidades em diferentes aspectos. O relator de cada grupo apresentou o quadro construído pelo seu GT. Utilizando os post-its colados no quadro do grupo, foi elaborado um painel geral dividido em duas colunas, separando as potencialidades e fragilidades. Todo o processo do design thinking for educators realizado no workshop, como um processo colaborativo e cocriativo, pode ser observado na Figura 7.

FIGURA 7 - Percurso do Workshop

PERCURSO DO PROCESSO DE DESIGN THINKING NA PRÁTICA DO WORKSHOP COCRIATIVO

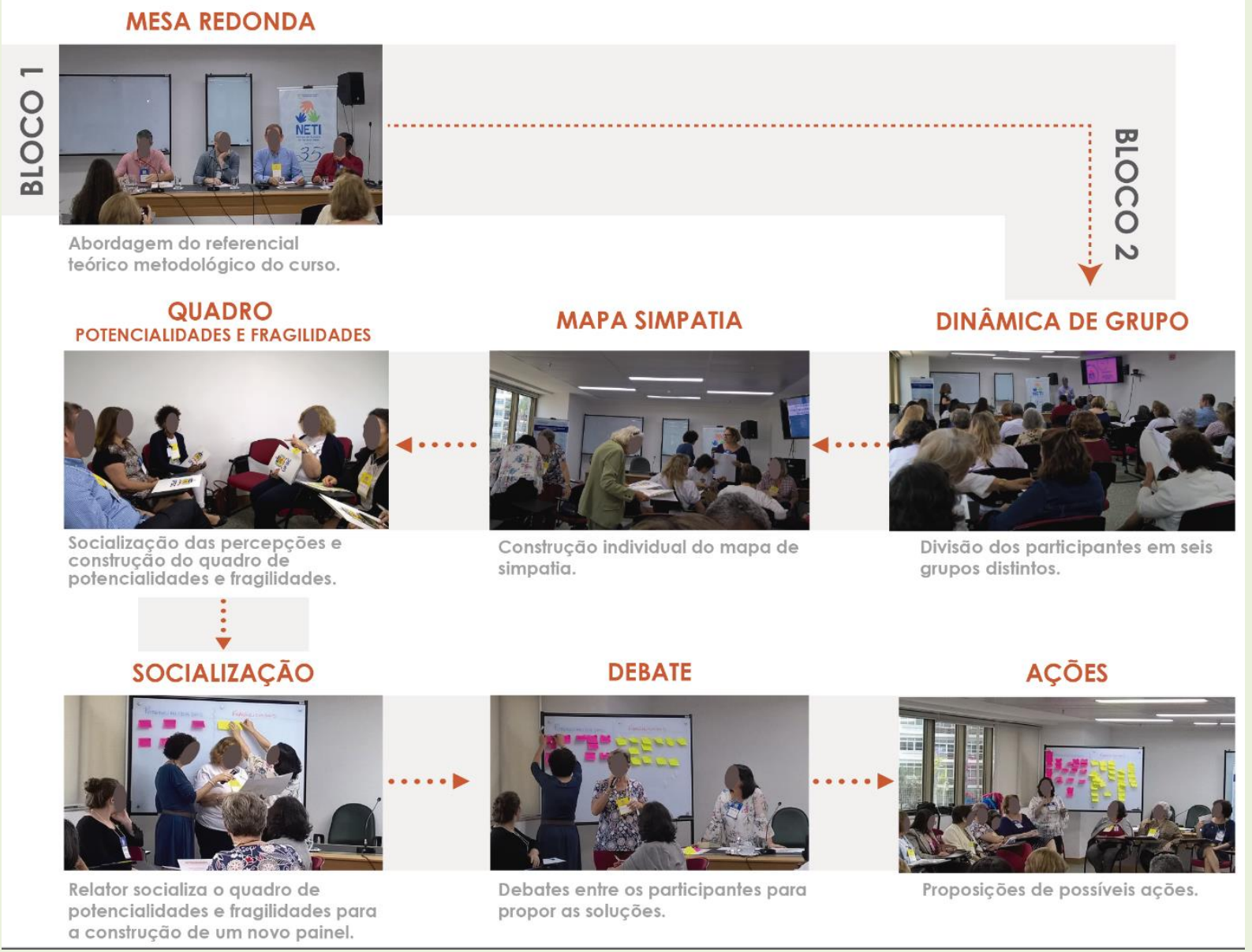

Fonte: [Elaborado pelos autores].

Revista Exitus, Santarém/PA, Vol. 10, p. 01-31, e020120, 2020. 
A partir da construção do painel coletivo, adotou-se a técnica de brainstorming (tempestade de ideias), para a geração de ideias e a conversão das principais fragilidades em oportunidades para 0 curso, conforme pode ser observado na parte inferior da Figura 7.

Com o debate coletivo foi possível socializar as principais dores, e a formulação de ideias e soluções para estas. A discussão pautou-se em quatro pontos: 1) aumento da carga horária do curso, 2) ampliação das atividades práticas, 3) aproximação com entidades representativas na área da pessoa idosa e 4) maior integração com a universidade.

Durante a fase ideação, as principais ideias e dores discutidas foram registradas pela equipe técnica e de facilitadores que atuaram no workshop. Finalizado essas atividades, o evento foi encerrado, e os resultados serão utilizados na quarta fase (EXPERIMENTAÇÃO), a qual compreende os passos 4.1 Crie protótipos e 4.2 Obtenha feedbacks (DT TOLKIT, 2011), conforme pode ser observado na Figura 8.

FIGURA 8 - Fase 4 - Experimentação

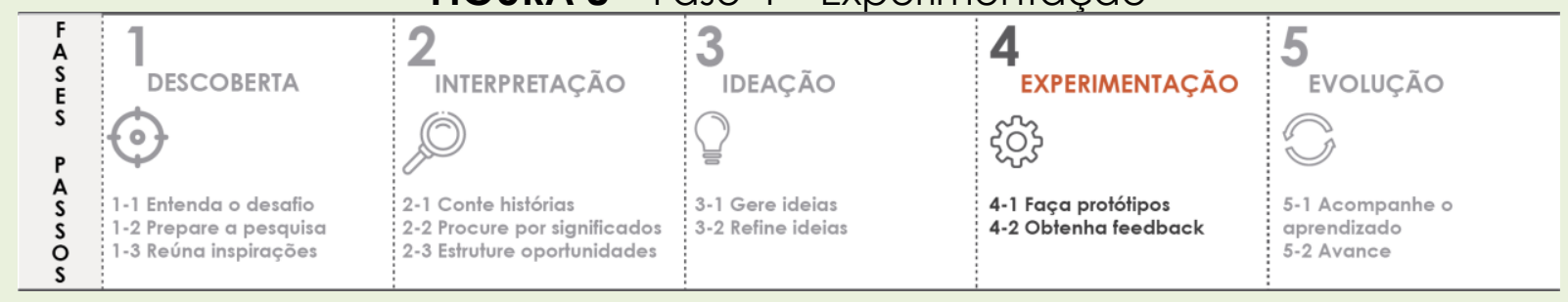

Fonte: [Elaborado pelos autores].

Esta fase foi realizada após a finalização do evento, e com os resultados obtidos no workshop, nos quais foram registradas as percepções dos participantes sobre o Curso nos materiais 1) mapa de simpatia e 2) quadro de fragilidades e potencialidades. As respostas em cada um dos materiais foram compiladas em planilha do google drive, e posteriormente diagramados em nuvens de palavras pela equipe técnica.

Os principais apontamentos realizados pelos participantes no workshop, são relativos ao 1) aumento da carga horária do curso, 2) ampliação das atividades práticas, 3) aproximação com entidades 
representativas na área da pessoa idosa e 4) integração com demais departamentos da UFSC, conforme podem ser observados na Figura 9.

FIGURA 9 - Resultados obtidos com os materiais em nuvem de palavras

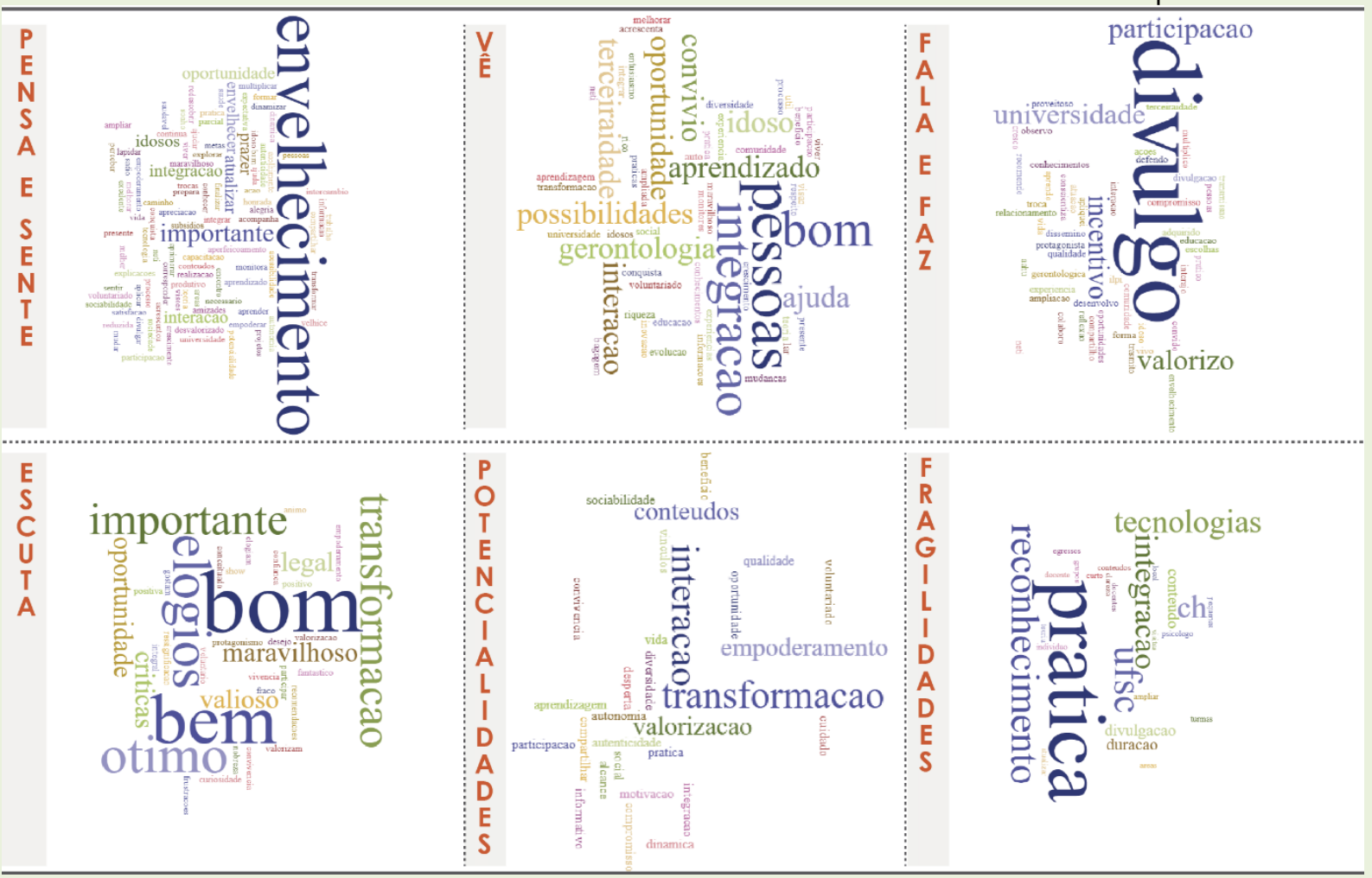

Fonte: [Elaborado pelos autores].

A luz dos resultados alcançados, optou-se pela redação de um novo Projeto Pedagógico de Curso (PPC). A redação desta proposta está sendo realizada pela equipe técnica, levando em consideração os resultados do workshop e as aspirações dos estudantes do curso. O PPC é um protótipo da prática educacional de um curso. É um documento inacabado, dinâmico e em constante modificação.

Neste interím, o projeto foi delineado e implementado. O curso continua estruturado em 4 módulos (4 semestres), com novas unidades curriculares. Antes o curso possuía três unidades curriculares por semestre. E na nova proposta, há seis unidades curriculares por semestre, com temas atuais sobre o envelhecimento humano. Os conteúdos do curso estão dispostos em diferentes áreas, como pode ser observado nas seguintes unidades curriculares: Introdução ao estudo do Envelhecimento e da Velhice; Noções de Filosofia e Envelhecimento; Noções de Psicologia e 
Envelhecimento; Mídias Digitais Atuais; Políticas de Direitos da Pessoa Idosa; Noções de Saúde e Envelhecimento; Família, Sociedade e Envelhecimento; Gerontologia Ambiental e Serviços Gerontológicos.

Estas unidades curriculares estão distribuídas nestes quatro semestres. As unidades curriculares foram estruturadas em forma de oficina, que podem ser ministradas por diferentes docentes, tendo em vista a rotatividade dos professores voluntários. Além destas unidades, o curso possui duas unidades específicas de base que são realizadas todos os semestres: 1) Projeto de vida para Ação Comunitária e 2) Seminário Reflexivo. O projeto de vida, de forma sintetizada, é uma unidade prática para o exercício de um plano de vida para o envelhecimento, alicerçado na prática do voluntariado junto a comunidade. E o seminário reflexivo, está estruturado de acordo com o Livro Educação: um tesouro a descobrir, em que apresenta os quatro pilares de uma educação para o século XXI; 1) aprender a conhecer, 2) aprender a fazer, 3) aprender a conviver e 4) aprender a ser (DELORS, 2000). Neste seminário, os estudantes realizam apresentações sobre temas estudados no respectivo semestre, em aderência aos pilares supracitados. Cada pilar também é estruturante do respectivo módulo.

Estas unidades curriculares estão distribuídas em cargas horárias práticas e teóricas, em atenção ao disposto no apontamento (2) dos estudantes, que indicam a necessidade de mais atividades práticas. Isso também justifica a organização das unidades em oficinas temáticas.

Até o presente, foi ofertado os dois primeiros módulos para a primeira turma do curso com esta proposta. Ao término do segundo semestre, realizou-se uma nova avaliação, para obter um feedback da turma sobre a proposição. Os estudantes responderam um questionário (google forms). Os resultados do questionário foram discutidos com a turma em sala de aula, e são considerados no planejamento dos próximos semestres do curso.

Na quarta fase (EVOLUÇÃO), são indicados os passos 5.1 Acompanhe o aprendizado e 5.2 Avance (DT TOLKIT, 2011), conforme apresentados na Figura 10. O acompanhamento da aprendizagem dos estudantes e a implementação da nova proposta, está sendo observada constantemente 
pelo coordenador do curso, o qual participa de todas as aulas do curso, e permanece atento às necessidades dos estudantes, docentes e do curso. Estas observações são sempre debatidas entre a equipe que está trabalhando no protótipo do PPC.

FIGURA 10 - Fase 5 - Evolução

\begin{tabular}{|c|c|c|c|c|c|}
\hline $\begin{array}{ll}\text { F } \\
\text { S } \\
\text { E } \\
S\end{array}$ & 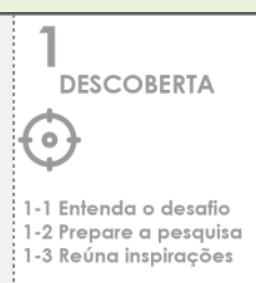 & 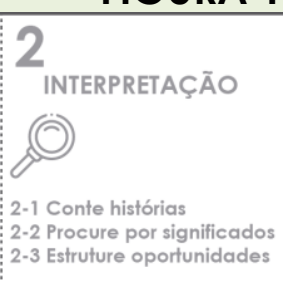 & $\begin{array}{l}3 \\
\text { IDEAÇĀO } \\
? \\
\varrho \\
\text { 3.1 Gere iddias } \\
3.2 \text { Refine ideias }\end{array}$ & 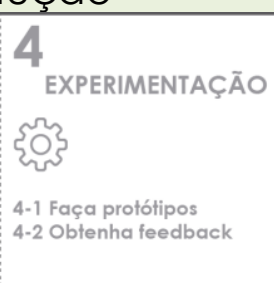 & 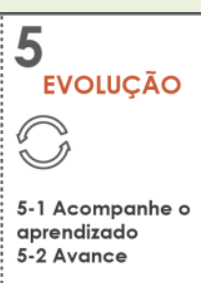 \\
\hline
\end{tabular}

Fonte: [Elaborado pelos autores].

O progresso do trabalho é registrado em documentos e ferramentas, assim como na forma desta pesquisa. O projeto segue avançando e já tem novos planos. Com a finalização da oferta desta primeira turma neste formato, será novamente realizada a segunda avaliação com os estudantes, com vistas ao aperfeiçoamento constante da proposta e do Projeto Pedagógico do Curso.

\section{CONSIDERAÇÕES FINAIS}

Diante dos resultados obtidos foi possível compreender como a participação do estudante no processo de avaliação de curso é relevante e fundamental para identificar oportunidades de melhorias. Nesse sentido, todos os passos sucessivos utilizados neste artigo para avaliar um curso de extensão para idosos, foi baseado no processo do Design Thinking for Educators (DT TOOLKIT, 2011). Assim, pode-se afirmar que executar os passos do processo de design thinking for educators na avaliação do referido curso, propiciou êxito na descoberta dos desafios, retomada e planejamento de ações futuras.

Além disso, este processo demonstrou-se satisfatório para a obtenção dos resultados, auxiliando na sistematização do processo avaliativo, e principalmente reforçando um dos principais preceitos das UNATIs, o protagonismo do idoso, considerando suas especificidades tanto físicas 
quanto cognitivas. Esta participação do idoso no processo, faz-se necessária pois configura uma avaliação centrada no estudante, o que potencializa seu aprendizado ao longo do curso.

Outro ponto a ser destacado neste artigo, é a composição de equipes multiprofissionais, ou seja, a integração de profissionais de diferentes áreas durante o processo de avaliação do curso. Esta integração com docentes, equipe técnica, discentes de graduação envolvidos na UNATI, além do estudante idoso, oportunizou uma construção criativa e colaborativa das questões abordadas durante a avaliação, o que reforça a cocriação ao longo de seu desenvolvimento, proporcionando uma avaliação efetiva e centrada nas necessidades reais dos estudantes.

Mediante aos resultados positivos desta pesquisa, com a compreensão e demonstração da aplicação do processo de design thinking for educators, sugere-se como estudos futuros a aplicação da metodologia em outros contextos educacionais de avaliação de curso, em diferentes modalidades de ensino, tendo em vista sua dinâmica cocriativa e de protagonismo do estudante no planejamento educacional.

\section{REFERÊNCIAS}

ALENCAR, M. S. S.; CARVALHO, C. M. R. G. O envelhecimento pela ótica conceitual, sociodemografica e político-educacional: ênfase na experiência piauiense. Interface: Comunicação, Saúde, Educação, v. 13, n. 29, p. 435444, 2009. Disponível em: <https://www.scielo.br/scielo.php?script=sci_arttext\&pid=S141432832009000200015>. Acesso em: 25 jun. 2020.

ASSOCIAÇÃO INTERNACIONAL DAS UNIVERSIDADES DA TERCEIRA IDADE (AIU3A). Histórico. Disponível em: <http://aiu3a.com/HISTORIQUE.html>. Acesso em: 26 maio 2020.

ARROYO, D. M. P.; ROCHA, M. S. P. M. L. Meta-avaliação de uma extensão universitária: Estudo de caso. Avaliação: Revista da Avaliação da Educação Superior, v. 15, n. 2, p. 135-161, 2010. Disponível em: <http://periodicos.uniso.br/ojs/index.php/avaliacao/article/view/863/862>. Acesso em: 25 maio 2020.

\section{BARTNIK, F. M. P. Ação extensionista em universidades católicas e} comunitárias e sua avaliação. 2009. 131 f. Dissertação (Mestrado) - Programa 
de Pós-graduação em Educação, Pontifícia Universidade Católica de Campinas, São Paulo, 2009. Disponível em:

$<$ http://tede.bibliotecadigital.puc-

campinas.edu.br:8080/jspui/bitstream/tede/629/1/Fabiana\%20Marques\%20P ereira\%20Bartnik.pdf>. Acesso em: 25 maio 2020.

BRASIL. Lei $\mathrm{n}^{\circ} \mathbf{1 0 . 8 6 1}$, de 14 de abril de 2004. Institui o Sistema Nacional de Avaliação da Educação Superior - SINAES e dá outras providências. Diário Oficial da União: seção 1, Brasília, DF, 2004. Disponível em:

<http://www.planalto.gov.br/ccivil_03/_ato2004-2006/2004/lei//10.861.htm>. Acesso em: 25 maio 2020.

BROWN, T. Design Thinking. Harvard business review, v. 86, n. 6, p. 84-92, 2008. Disponível em: <https://hbr.org/2008/06/design-thinking>. Acesso em: 25 maio de 2020.

BROWN, T. Design Thinking: uma metodologia poderosa para decretar o fim das velhas ideias. Rio de Janeiro: Elsevier, 2010.

CACHIONI, M.; ORDONEZ, T. N. Universidade da Terceira Idade. In: FREITAS, E. V.; PY, L. Tratado de geriatria e gerontologia. 4. ed. Rio de Janeiro:

Guanabara Koogan, 2017. p. 1604-1612.

CACHIONI, M. Universidade da Terceira Idade: história e pesquisa. Revista Kairós Gerontologia, São Paulo, v. 15, n. 7, p. 01-08, 2012. Disponível em: <https://revistas.pucsp.br/kairos/article/view/15225/1 1354>. Acesso em: 28 maio 2020.

COOPER, R.; JUNGINGER, S.; LOCKWOOD, T. Design thinking and design management: A research and practice perspective. In:

LOCKWOOD, T. (Org.). Design thinking. New York, NY: Allworth Press, p. 57-64, 2010.

DELORS J. (Org.). Educação: um tesouro a descobrir. São Paulo: Cortez; Brasilia: MEC: UNESCO, 2000.

DOLL, J. A Educação no Processo de Envelhecimento. In: PY, E. V. F. L. Tratado de geriatria e gerontologia. Rio de Janeiro: Guanabara Koogan, 4. ed., p. 1598-1603, 2017.

D. SCHOOL. Bootcamp Bootleg. Escola de Design Thinking da Universidade Stanford, 2011. Disponível em: <http://dschool.stanford.edu/wpcontent/uploads/2011/03/BootcampBootleg2010v2SLIM.pdf>. Acesso em: 28 jun. 2020.

DT TOOLKIT. Design Thinking for Educators. Toolkit, 1. ed. IDEO and Riverdale Country School, abr. 2011. 
FACHIN, O. Fundamentos de metodologia. 5. ed. [rev.]. São Paulo: Saraiva, 2006.

IDEO. Human Centered Design Toolkit, 2009. Disponível em:

<http://www.ideo.com/work/human-centered-design-toolkit>. Acesso em: 28 jun. 2020.

KIELING, A. P., et al. Aspectos Interdisciplinares em Design Thinking - um enfoque na Administração de Negócios, Moda e Psicologia Social.

Simpósio Internacional sobre Interdisciplinaridade no Ensino na Pesquisa e na Extensão - Região Sul, 2013.

KIT DT. Design Thinking para Educadores. 1. ed. Versão em Português: Instituto Educadigital, 2014. Disponível em: <http://www.dtparaeducadores.org.br/> Acesso em: 20 dez. 2019.

MARCONI, M. A.; LAKATOS, E. M. Técnicas de pesquisa: planejamento e execução de pesquisas, amostragens e técnicas de pesquisas, elaboração, análise e interpretação de dados. 6. ed. São Paulo: Atlas, 2007.

MERRIAM, S. B. Qualitative research: a guide to design and implementation. San Francisco: Jossey-Bass/Wiley, 2009.

NETI (NÚCLEO DE ESTUDOS DA TERCEIRA IDADE). Apresentação. Florianópolis, 2020. Disponível em: <https://neti.ufsc.br/apresentacao/>. Acesso em: 23 jul. 2020.

PEREIRA, D. Mapa de Empatia: O que é. O Analista de modelos de negócios. [S.I] , 2017. Disponível em: <https://analistamodelosdenegocios.com.br/mapade-empatia-o-que-e/>. Acesso em: 20 jul. 2020.

PETERSON, D. A. Who are the educational gerontologists? . Educational Gerontology: An International Quarterly, v. 5, n. 1, p. 65-77, 1980. Disponível em:

<https://www.tandfonline.com/doi/abs/10.1080/0360hyp800050105?journalC ode=uedg20>. Acesso em: 25 maio 2020.

POLÍTICA NACIONAL DE EXTENSÃO UNIVERSITÁRIA. Fórum de Pró-Reitores das Instituições Públicas de Educação Superior Brasileiras. Manaus, 2012.

Disponível em: <http://proex.ufsc.br/files/2016/04/Política-Nacional-deExtensão-Universitária-e-book.pdf>. Acesso em: 25 maio 2020.

REBOUÇAS, M. et al. O que há de novo em ser velho. Saúde e Sociedade, São Paulo, v. 22, n. 4, p.1226-1235, 2013. Disponível em:

<https://www.revistas.usp.br/sausoc/issue/view/5879>. Acesso em 20 jun. 2020. 
RIVERDALE. School History. Disponível em: <http://www.riverdale.edu/> Acesso em: 25 jun. 2020.

SAMPIERI, R. H.; COLLADO, C. F.; LUCIO, M. P. B. Metodologia de Pesquisa. 5. ed. Porto Alegre: Penso, 2013.

SINAES (SISTEMA NACIONAL DE AVALIAÇÃO DA EDUCAÇÃO SUPERIOR). Apresentação, 2020. Disponível em: <http://portal.mec.gov.br/sinaes>. Acesso em: 18 maio 2020.

UFSC (UNIVERSIDADE FEDERAL DE SANTA CATARINA). Câmara de Pesquisa e Extensão. Parecer $\mathbf{n}^{\circ} \mathbf{0 2 8} / \mathrm{CPE} / \mathbf{9 0}$. Florianópolis: UFSC, 12 mar. 1990. Disponível impresso. Acesso em: 23 jul. 2020.

UFSC (UNIVERSIDADE FEDERAL DE SANTA CATARINA). Resolução Normativa N $\mathbf{8 8 / 2 0 1 6 / C U n , ~ d e ~} 25$ de outubro de 2016. Dispõe sobre as normas que regulamentam as ações de extensão na Universidade Federal de Santa Catarina. Disponível em: <https://proex.ufsc.br/files/2016/1 1/Resolu\%C3\%A7\%C3\%A3oNormativa_88_Ex tens\%C3\%A3o.pdf>. Acesso em: 27 maio 2020.

VAHL, E. A. C.; GODTSFRIEDT, M. C.; GUEDES, N. M. Proposta Educacional do Núcleo de Estudos da Terceira Idade. Florianópolis: UFSC, 1991. 11 p.

VELLAS, P. As Oportunidades da Terceira Idade. Maringá: Edvem, 2009. 222 p.

VERAS, R. P.; CALDAS, C. P. Promovendo a saúde e a cidadania do idoso: o movimento das universidades da terceira idade. Ciência saúde coletiva, Rio de Janeiro, v. 9, n. 2, 2004. Disponível em:

$<\mathrm{http}$ ://www.scielo.br/scielo.php?script=sci_arttext\&pid=S1413-

$81232004000200018 \&$ Ing=en\&nrm=iso>. Acesso em: 26 maio 2020.

VIANNA, H. M. Avaliação de Cursos pelos Alunos: considerações. Estudos em Avaliação Educacional, v. 15, n. 29, 2004. Disponível em:

<http://publicacoes.fcc.org.br/ojs/index.php/eae/article/view/2162>. Acesso em: 18 maio de 2020.

Recebido em: 28 de agosto de 2020 Aprovado em: 17 de novembro de 2020 Publicado em: 15 de dezembro de 2020 